\title{
A rice $L S D 1$-like-type ZFP gene OsLOL5 enhances saline-alkaline tolerance in transgenic Arabidopsis thaliana, yeast and rice
}

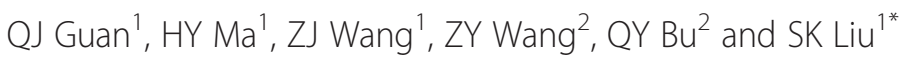

\begin{abstract}
Background: Zinc finger proteins (ZFPs) play an important role in regulating plant responses to abiotic stress. However, little is known about the function of LSD1-like-type ZFP in saline-alkaline (SA) stress resistance of rice. In this study, OsLOL5 (GenBank No. AJ620677), containing two LSD1-like-type C2C2 domains, was isolated and analyzed its protection roles in transgenic plants and yeast. OSLOL5 was located in the nucleus as evidenced by the bombardment of onion epidermal cells.

Results: OsLOL5 expression significantly increased in rice leaves and roots under $150 \mathrm{mmol} \mathrm{L}-1 \mathrm{NaCl}, 30 \mathrm{mM} \mathrm{NaHCO}$, and $10 \mathrm{mmol} L-1 \mathrm{H}_{2} \mathrm{O}_{2}$ treatment, respectively. Overexpression of OsLOL5 in yeast resulted in SA tolerance at significant level. Transgenic Arabidopsis plants overexpressing OsLOL5 grew well in the presence ofboth $\mathrm{NaCl}$ and $\mathrm{NaHCO}_{3}$ treatments, whereas wild-type plants exhibited chlorosis, stunted growth phenotype, and even death. SA stress caused significant changes in the malondialdehyde (MDA) contents in non-transgenic plants compared with those in transgenic lines. Transgenic rice overexpressing OSLOL5 exhibited stronger resistance than NT under $\mathrm{NaHCO}_{3}$ treatment, as demonstrated by its greater shoot length, and fresh weight. The genes associated with oxidative stress, such as OsAPX2, OsCAT, OsCU/Zn-SOD, and OsRGRC2, were significantly upregulated in OsLOL5overexpressing rice. The results suggested that OSLOL5 improved SA tolerance in plants, and regulated oxidative and salinity stress retardation via the active oxygen detoxification pathway.

Conclusions: The yeast INVSCl bacterium grew significantly better than the control strain under $\mathrm{NaCl}, \mathrm{NaHCO}_{3}$, and $\mathrm{H}_{2} \mathrm{O}_{2}$ treatments. These findings illustrated that OsLOL5 overexpression enhanced yeast resistance for SA stress through active oxygen species. The present study showed that the OSLOL5 genes involved in the ROS signaling pathways may combine with the model plant Arabidopsis and rice in LDS1-type ZFP by ROS signaling pathways that regulate cell necrosis. We speculated that the OsLOL5 active oxygen scavenging system may have coordinating roles. The present study further revealed that OsLOL5 ZFP could regulate oxidative stress function, but could also provide a basis for saltresistant rice strains.
\end{abstract}

Keywords: Rice, LSD1-like gene family, Transcription factor, OsLOL5, Arabidopsis thaliana, Saline-alkaline, Yeast

\footnotetext{
* Correspondence: shenkuiliu@nefu.edu.cn

'Key Laboratory of Saline-alkali Vegetation Ecology Restoration in Oil Field

(SAVER), Ministry of Education, Alkali Soil Natural Environmental Science

Center (ASNESC), Northeast Forestry University, No.26 Hexing Road, Nangang

District, Harbin City, Heilongjiang 150040, China

Full list of author information is available at the end of the article
} 


\section{Background}

Zinc finger proteins (ZFPs) are an important class of transcription factors. Zinc finger domains are the important feature of ZFPs, which consist of various numbers of cysteine $(\mathrm{C})$ and histidine residues $(\mathrm{H})$ combined with zinc ions [1]. Based on the number and location of these residues, ZFPs are classified into $\mathrm{C} 2 \mathrm{H} 2, \mathrm{C} 2 \mathrm{HC}$, $\mathrm{C} 2 \mathrm{HC} 5, \mathrm{C} 3 \mathrm{HC} 4, \mathrm{CCCH}, \mathrm{C} 2 \mathrm{C} 2, \mathrm{C} 4 \mathrm{HC} 3, \mathrm{C} 6$, and $\mathrm{C} 8$ groups [2]. Versatile ZFPs can bind DNA, RNA, proteins, and lipids to participate in the activities of an organism. C2H2 ZFPs are involved in different stages of plant growth and development and in various stress responses [3-9]. Plants possess a class containing the LSD1 zinc finger domain of the gene called the LSD1like gene family, which is typically characterized by the presence of one to three LSD1-like zinc finger domains $\left(\mathrm{C}-\mathrm{X}_{2}-\mathrm{C}-\mathrm{X}_{14}-\mathrm{C}-\mathrm{X}_{2}-\mathrm{C}\right)$. The LSD1-ke genes were found to be important in programmed cell death (PCD) and responses against diseases [1]. Furthermore, the Arabidopsis LSD1 gene responds to superoxide dismutase (SOD) signals, and suppresses PCD via AtLSD1 by upregulating the $\mathrm{Cu} / \mathrm{Zn}-\mathrm{SOD}$ gene to mit cell death proferation [10]. ZAT11, a zinc finger of $A$. thaana, is a dual-function transcriptional regulator that positively regulates primary root growth, but negatively regulates Ni21 tolerance [11]. The TaLOL2 gene contains three typical LSD1-ke zinc finger domains. qRT $-\mathrm{PCR}$ analysis showed that TaLOL2 is upregulated in early stripe rust infection, indicating the involvement of wheat stripe rust-induced defense responses [12].

To date, the ZFP transcription factor family in rice (Oryza sativa L.) has been a huge focus of stress research. After searching through the NCBI, Gramene, and Plant TFDB databases, we acquired the sequence data of 878 rice ZFP genes in 12 rice chromosomes. Among them, Chromosomes 1 and 11 contain 121 and 45 ZFP genes, respectively. Several ZTP gene functions have been characterized. A previous study showed that the ZFP gene results in certain yields and traits under abiotic stress related to cultivated rice [13]. For example, rice ZFP245 is low-temperature and drought stress-related [14]. Overexpression of ZFP182 in tobacco or rice increases tolerance for $\mathrm{NaCl}$ stress, thereby suggesting that $\mathrm{C} 2 \mathrm{H} 2-$ ZFP182 may be involved in the response of plants to salt stress [15]. Overexpression of OsTOP6A1 increases tolerance for $\mathrm{NaCl}$ and mannitol stress in A. thaliana [16]. OsZFP177 expression is induced during the cold season, drought, and upon exposure to $\mathrm{H}_{2} \mathrm{O}_{2}$ stress [17]. OsLSD1 gene over-expression can accelerate the differentiation of the callus and promote chlorophyll $\mathrm{b}$ accumulation in transgenic plants. Antisense transgenic plants OsLSD1 are characterized by spontaneous necrotic lesions, enhanced disease resistance, and upregulated PR1 gene expression [1]. OsLOL2 has two LSD1-ke zinc finger domains, and is important in rice growth and disease resistance. Overexpression of OsLOL2 in transgenic rice significantly improves bacterial bight resistance. Over-expressing transgenic tobacco enhances bacterial wilt disease and Pseudomonas syringae resistance [18, 19]. However, studies on salt tolerance in the gene OsLOL5 remain mited to date. In the present study, the OsLOL5 gene from rice leaves of cultivar LongJing11 (LJ11) was cloned using RT-PCR, and the mRNA expression levels under SA treatment were detected by using qRT-PCR and transgenic techniques. This study aimed to reveal the mechanisms of the OsLOL5 gene in regulating rice responses to SA stress.

\section{Methods}

Plant materials and stress treatment

A. thaliana (ecotype: Columbia) seeds for SA treatment were provided by the Environmental Research Center of Northeast Forestry University, Harbin City, Heilongjiang Province, China. aast Institute of Geography and Agroecology, Chinese Academy of Sciences, Harbin City, Heilongjiang province, China. Nine-day-old rice seedlings were used for $150 \mathrm{mmol} \mathrm{L}^{-1} \mathrm{NaCl}, 30 \mathrm{mmol} \mathrm{L}^{-1}$ $\mathrm{NaHCO}_{3}$, and $5 \mathrm{mmol} \mathrm{L} \mathrm{H}_{2} \mathrm{O}_{2}$ stress treatments. Leaf and root samples were collected after treatment and immediately frozen in quid nitrogen. RNA was extracted using an RNeasy Plant Mini Kit (Qiagen, Dusseldorf, Germany) and then stored at $-80{ }^{\circ} \mathrm{C}$ in the Northeast Institute of Geography and Agroecology, Chinese Academy of Sciences, Harbin City, Heilongjiang Province, China. Each stress treatment was repeated six times.

\section{Cloning of OsLOL5 gene}

The full-length OsLOL5 cDNA sequence was obtained by RT-PCR using primer pair OsLOL5-P1, which was designed based on the gene sequence in GenBank (AJ620677, http://www.ncbi.nlm.nih.gov/nuccore/40809630?report=genbank). The total RNA was isolated from four leaves from rice seedlings of LJ11 using Trizol (Invitrogen, Carlsbad, CA, USA) according to the manufacturer's instructions. First-strand cDNA was synthesized using a SuperScript ${ }^{\mathrm{III}}$ reverse transcriptase kit. The specific primer pair OsLOL5-P1 was designed with Primer Premier 5.0 (Premier Biosoft, Palo Alto, USA) and used for full-length ampfication of the gene, which was cloned into the pMD18-T(Takara Biotechnology in DAAN) vector and confirmed through sequencing (Invitrogen, Shanghai, China).

\section{Subcellular localization of OsLOL5 by transient expression in onion epidermal tissue}

To determine the subcellular location of the OsLOL5 protein, the PCR product generated by primer pair OsLOL5P2 was used to construct the PBI121::OsLOL5::GFP 
expression vector (Fig. 1). The PBI121-OsLOL5::GFP fusion plasmids were coated onto $20 \mathrm{ml}$ of $50 \mathrm{mg} \cdot \mathrm{mL}^{-1}$ gold particles with $2.5 \mathrm{M} \mathrm{CaCl}_{2}$ and $0.1 \mathrm{~mol} \mathrm{~L}^{-1}$ spermidine and mixed rigorously using a vortex for $2 \mathrm{~min}$. Plasmid-coated particles were dehydrated using 75 and $95 \%$ ethanol prior to bombardment. Single-layer epidermal sheaths peeled from onion bulbs were placed on 1/2 MS plates and subjected to particle bombardment using the standard procedure provided by the manufacturer. Plasmid-coated gold particles were accelerated with a helium burst at 1100 psi in a PDS-1000/He instrument (Bio-Rad, Hercules, California, USA). Plates containing transfected onion tissues were wrapped in foil and incubated in the dark overnight $(16-20 \mathrm{~h})$ at room temperature [20].

\section{OsLOL5 gene expression analysis}

Total RNA was extracted from roots and leaves after treatment of the seedlings with $150 \mathrm{mmol} \mathrm{L}^{-1} \mathrm{NaCl}$, $30 \mathrm{mmol} \mathrm{L}^{-1} \mathrm{NaHCO}_{3}$, or $5 \mathrm{mmol} \mathrm{L}^{-1} \mathrm{H}_{2} \mathrm{O}_{2}$ after different periods of time ( $0 \mathrm{~h}$ as control group, 12,24 , and $48 \mathrm{~h}$ ), respectively. First-strand cDNA was synthesized from $1 \mu \mathrm{g}$ of total RNA with SuperScript ${ }^{\circ} I I I$ reverse transcriptase and oligo-dT primers (Invitrogen, Shanghai, China) according to the manufacturer's instructions. cDNA was diluted with nuclease-free water to 1:10. Aliquots of the same cDNA sample were used for real-time PCR with primer pair OsLOL5-P3. The OsActin1 gene was used as an internal control. PCR was performed in a $25 \mu \mathrm{L}$ reaction mixture containing $400 \mathrm{nmol} \mathrm{L}{ }^{-1}$ of each primer, $1 \times$ SYBR Green qPCR master mix (Agilent Technologies, Santa Clara, CA, USA), and approximately $30 \mathrm{ng}$ of cDNA. Real-time PCR was performed on the Agilent Stratagene MxPro-Mx3000p (Agilent Technologies, Santa Clara, CA, USA) using the following procedure: $30 \mathrm{~s}$ at $95{ }^{\circ} \mathrm{C}$ for denaturation, followed by 40 cycles of $5 \mathrm{~s}$ at $94{ }^{\circ} \mathrm{C}, 30 \mathrm{~s}$ at $60{ }^{\circ} \mathrm{C}$, and $40 \mathrm{~s}$ at $72{ }^{\circ} \mathrm{C}$. Relative transcript abundance was calculated according to the manufacturer's instructions. The specificity of each primer pair was verified by determining the melting curves at the end of each run, and sequencing the amplified bands from gel electrophoresis.

\section{Analysis of sensitivity to abiotic stress in OsLOL5 transgenic yeast}

To detect OsLOL5 response to $\mathrm{NaCl}, \mathrm{NaHCO}_{3}$, and $\mathrm{H}_{2} \mathrm{O}_{2}$, OsLOL5 was amplified using primer pair OsLOL5-P4, and the PCR product was cloned into pMD18-T. OsLOL5 was cut from pMD18-T with restriction endonucleases KpnI and SphI, and ligated into the yeast expression vector pYES2. Using the LiAc method, the plasimds $p Y E S 2$ and pYES2::OsLOL5 (Fig. 1) were transformed into the Saccharomyces cerevisiae strain INVSc1.Transformed yeast strains were grown in synthetic defined medium minus the appropriate amino acids (SD-Ura) for selective growth for the expression plasmids. To analyze abiotic stress tolerances, the pYES2- and pYES2::OsLOL5transformed cell cultures were adjusted to an $\mathrm{OD}_{600}$ of 0.6 using yeast extract-peptone-dextrose (YPD) medium. Ten-fold serial dilutions of yeast strains were prepared, and $5-\mu \mathrm{l}$ aliquots of each dilution were spotted on solid YPD medium containing $\mathrm{NaCl}\left(0 \mathrm{~mol} \mathrm{~L}^{-1}\right.$ as control group, 0.8 , and $\left.1 \mathrm{~mol} \mathrm{~L}^{-1}\right), \mathrm{NaHCO}_{3}$ (30, 32, and $\left.40 \mathrm{mmol} \mathrm{L}^{-1}\right)$, or $\mathrm{H}_{2} \mathrm{O}_{2}\left(3,3.2\right.$, and $\left.3.4 \mathrm{mmol} \mathrm{L}^{-1}\right)$. All of the plates were incubated at $30^{\circ} \mathrm{C}$ for $3-6$ days.

\section{Functional analysis of OsLOL5 in Arabidopsis}

Using primer pair OsLOL5-P4, the OsLOL5 PCR product was ligated into the expression vector pCXSN after XcmI digestion [21]. For Arabidopsis transformation, the $p C X S N:: O s L O L 5$ (Fig. 1) vectors were first introduced into Agrobacterium tumefaciens GV3101 by electroporation. Arabidopsis cv Col-0 plants were transformed via floral dip method as previously described [22]. Arabidopsis transgenic seeds were plated on half-strength Murashige and Skoog (MS) medium containing $25 \mathrm{mg} \cdot \mathrm{L}^{-1}$ hygromycin for selection. Resistant plants were used for molecular identification. To study the function of OsLOL5 in the abiotic stress response, the transgenic T3 generation

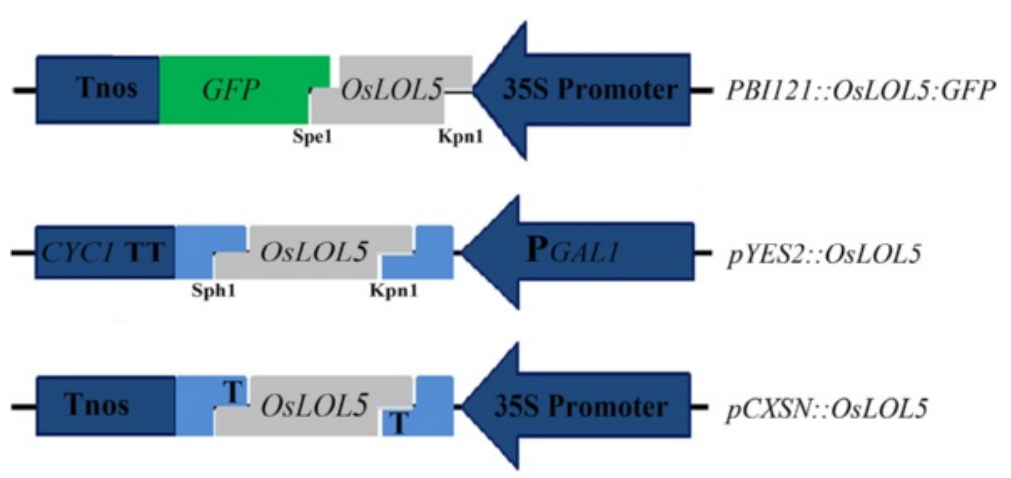

Fig. 1 Schematic of the expression vectors PB/121::OSLOL5::GFP, pCXSN::OSLOL5, and pYES2::OsLOL5. 35S Promoter, Cauliflower Mosaic Virus 35S Promoter; Tnos, nos-terminator; PGAL1, Galactokinase promoter; CYC1 TT, CYC1 terminator; and GFP, green fluorescent protein 
encoding OsLOL5 driven by the cauliflower mosaic virus (CaMV35S) promoter were tested with primer pair OsLOL5-P5 and then used for the following studies. The T3 (\#1-\#3) and WT seeds were sterilized and sowed in 1/ 2 MS medium for germination for $10 \mathrm{~d}$. The seedlings were then transferred to $1 / 2 \mathrm{MS}$ medium containing 0 (0 $\mathrm{mmol} \mathrm{L}^{-1}$ as control group), 100,125 , or $150 \mathrm{mmol} \mathrm{L}^{-1}$ $\mathrm{NaCl}$ or $0,2,4$, and $6 \mathrm{mmol} \mathrm{L}^{-1} \mathrm{NaHCO}_{3}$. After $30 \mathrm{~d}$, the growth phenotype, plant height, fresh weight, and MDA content of the seedlings were measured.

\section{Alkaline stress tolerance analysis of OsLOL5 in rice} For rice transformation, the pCXSN::OsLOL5 vectors were transferred into A. tumefaciens EHA105 through electroporation. OsLOL5 was transformed into O. sativa L. ssp. japonica cv. "Longjing 11" by using the Agrobacterium-mediated co-cultivation method. The transgenic T2 generation encoding OsLOL5 driven by the cauliflower mosaic virus (CaMV35S) promoter were tested with primer pair OsLOL5-P5. OsOLO5 expression in transgenic plants was confirmed by using Northern blot. Three independent T2 homologous transgenic lines and the control Longjing 11 were used for alkaline stress tolerance experiments. For alkaline treatment, concurrent buds were transferred to the stress liquid culture medium containing $0\left(0 \mathrm{mmol} \mathrm{L}^{-1}\right.$ as control group), 5, 7.5, and $10 \mathrm{mmol} \mathrm{L}^{-1} \mathrm{NaHCO}_{3}$. After $21 \mathrm{~d}$, the growth phenotype, root length, fresh weight, and MDA content of seedlings were measured. Simultaneously, the expression level of oxidative stress response genes OsAPX2 (AB053297), OsCAT (AB020502), OsCu/ $\mathrm{Zn}$-SOD (AK059841), and OsRGRC2 (AY136765) were analyzed. Procedures for RNA extraction and real-time PCR were similar to those described and listed in Table 1.

\section{MDA content measurements}

MDA content was determined using the previously described thiobarbituric acid reaction [23]. Absorbance levels at 532 and $600 \mathrm{~nm}$ were determined using a spectrophotometer. After subtracting the non-specific absorbance at $600 \mathrm{~nm}$, MDA concentration was determined using its extinction coefficient $155 \mathrm{mM}^{-1} \cdot \mathrm{cm}^{-1}$.

\section{Data analysis}

Analysis of variance (AVONA) and multiple comparison by software data processing system (DPS) (version 7.05).

\section{Results}

\section{OsLOL5 is a LSD1-like zinc finger gene}

OsLOL5 was successfully cloned using RT-PCR with specific primer pair OsLOL5-P1 from O. sativa L. ssp. cv. "LongJing 11" with alkaline stresses then inserted into the pMD18-T vector. Sequencing results confirmed that the OsLOL5 sequence was identical to GenBank No. AJ620677. Sequence analysis showed that the full-length sequence encoded 163 amino acids, with predicted molecular mass and isoelectric point of $17.6 \mathrm{kDa}$ and 6.03 , respectively. Based on structural properties indicated by SMART programs, the predicted protein contains two LSD1-like zinc finger domains. The LSD1-like zinc finger domains contain the sequence $\mathrm{C}-\mathrm{X}_{2}-\mathrm{C}-\mathrm{X}_{14}-\mathrm{C}-\mathrm{X}_{2}-\mathrm{C}$, where $\mathrm{X}$ can be any amino acid. The subscripts indicate the number of residues. Homology alignment analysis using ClustalX software showed that the deduced amino acid sequences were highly similar to several previously isolated LSD1-like ZFPs in Arabidopsis and rice (Additional file 1: Figure S1). We also found that OsLOL5 was clustered in the same group with AtLOL2 because they share the highest similarity in terms of identities. Therefore, OsLOL5 was determined to be an LSD1-like ZFP.

\section{OsLOL5 localized in the nucleus}

Online analysis tool Psort predicted that OsLOL5 would localize in the nucleus and cytoplasm with 47.8 and $34.8 \%$ probability, respectively. To verify the prediction, a pBI121::OsLOL5::GFP plasmid was transformed into onion epidermal cells using gene gun bombardment.

Table 1 The primers used in gene clone and qRT-PCR

\begin{tabular}{lll}
\hline Primer name & Forward (5'-3') & Reverse $\left(5^{\prime}\right.$-3') $\left.^{\prime}\right)$ \\
\hline OsLOL5-P1 & GATGTCTCAGCTACCACTTGCA & GGTCACCTTCCTGTCTACAT \\
OsLOL5-P2 & GGTACCATGTCTCAGCTACCACTTGC & ACTAGTGGCTTCAGCTAGCCCTGAT \\
OsLOL5-P3 & GCAACCCACAAGAACTAACTCATC & GGCTTGTCCATACCATCTTGAAC \\
OsActin1 & CTTCATAGGAATGGAAGCTGCGGGTA & CGACCACCTTATCTTCATGCTGCTA \\
OsLOL5-P4 & GGTACCATGTCTCAGCTACCACTTGC & GCAACCCACAAGAACTAACTCATC \\
OsLOL5-P5 & GGTACCATGTCTCAGCTACCACTTGC & ATCGGGGAATTCGCTAGTG \\
OsAPX2P1 & CGGCGTAATCCGCAAAGAAG \\
OsCATP1 & TCCTACGCCGACTTCTACCA & TCCTACATGCTCGGCTTCG \\
OsCU/Zn-SODP1 & GGTTGCCTCAG CTACACCTT \\
OsRGRC2P1 & TACTTCCCATCCCGCTACGA & CCAGCATAACAACCGCACAC \\
\hline
\end{tabular}




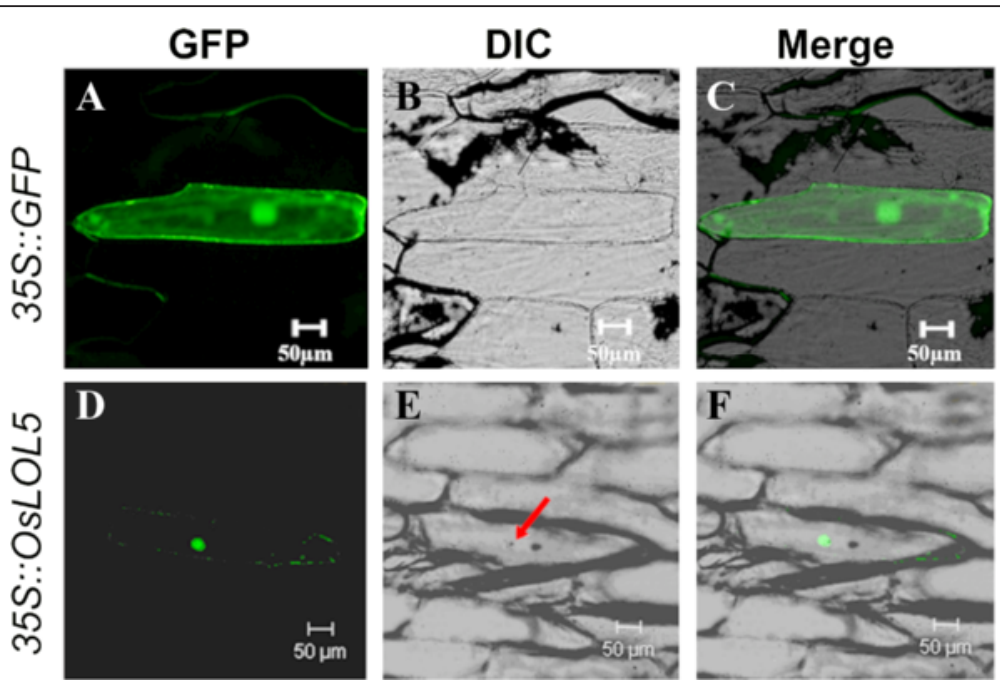

Fig. 2 Subcellular localization of the 35S::OsLOL5::GFP fusion protein. a, d GFP, green fluorescence. b, e DIC, bright field. c, f Merge, green fluorescence, and bright field superposition. Nucleus is marked with the red arrow

Cells were cultured for $18-24 \mathrm{~h}$ in the dark, and the transformed onion epidermal cells were observed for GFP signals using laser confocal fluorescence microscopy. When driven by promoter $35 \mathrm{~S}$, fusion protein OsLOL5::GFP was expressed in onion epidermal cells with green fluorescence in the nucleus, thereby suggesting that OsLOL5 localized in the nucleus (Fig. 2).

\section{Expression pattern of OsLOL5 under abiotic stress treatments}

To obtain an overview of the OSLOL5 expression pattern under different abiotic stress conditions, qRT-PCR was performed to examine its transcript in rice after saline, alkaline, and oxidative stress treatments. OsLOL5 expression was significantly induced in both leaves and roots by $150 \mathrm{mmol} \mathrm{L}^{-1} \mathrm{NaCl}$ treatment. The maximum 17.7-fold increase compared with the untreated control in leaves occurred $48 \mathrm{~h}$ after treatment, but a 5.8 -fold increase compared with the control in roots occurred $24 \mathrm{~h}$ after treatment (Fig. 3a). OsLOL5 was upregulated in leaves and roots subjected to $30 \mathrm{mmol} \mathrm{L} \mathrm{NaHCO}_{3}$ treatment and peaked after $24 \mathrm{~h}$. OsLOL5 expressions were 19- and 6fold higher than the untreated control in leaves and roots, respectively (Fig. 3b). OsLOL5 expression dramatically increased by 25 -fold in leaves after $24 \mathrm{~h}$ of $5 \mathrm{mmol} \mathrm{L}-1 \mathrm{H}_{2} \mathrm{O}_{2}$ treatment compared with the untreated control (Fig. 3c). However, $\mathrm{H}_{2} \mathrm{O}_{2}$ treatment had no significant effect in OsLOL5 expression in roots. OsLOL5 was a stressresponsive ZFP, and exhibited differential expression patterns in leaves and roots under SA treatments.

\section{OsLOL5 improved yeast tolerance to $\mathrm{NaHCO}_{3}$ and $\mathrm{H}_{2} \mathrm{O}_{2}$} To gain a preliminarily understanding of the function of OsLOL5 in abiotic stress, we surveyed growth characteristics

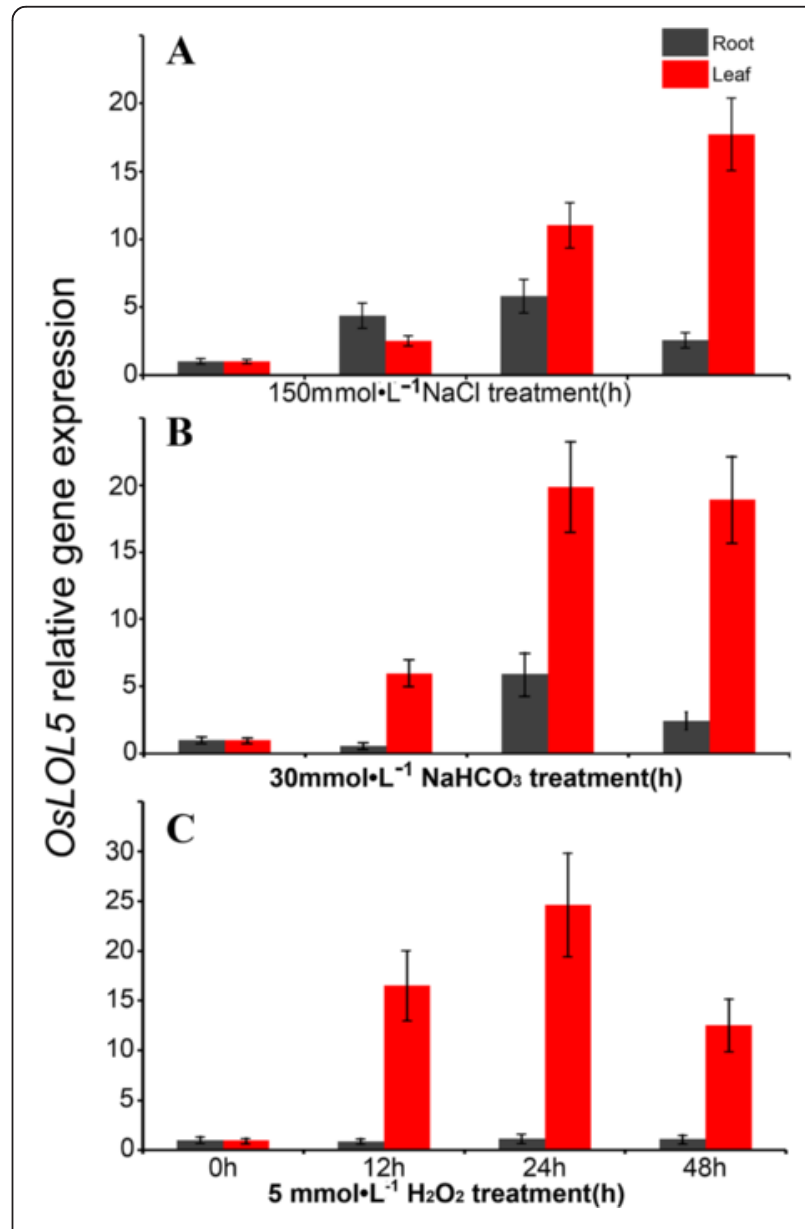

Fig. 3 Real-time quantitative expression analysis of the OsLOL5 gene under a salt $\left(150 \mathrm{mmol} \mathrm{L}^{-1} \mathrm{NaCl}\right)$, b alkali $\left(30 \mathrm{mmol} \mathrm{L}^{-1} \mathrm{NaHCO}_{3}\right)$, and c oxidative ( $5 \mathrm{mmol} \mathrm{L}^{-1} \mathrm{H}_{2} \mathrm{O}_{2}$ ) stress treatments, respectively 


$$
10^{-1} 10^{-2} 10^{-3} 10^{-4} 10^{-5} \quad 10^{-1} 10^{-2} 10^{-3} 10^{-4} 10^{-5} \quad 10^{-1} 10^{-2} 10^{-3} 10^{-4} 10^{-5}
$$

\begin{tabular}{|c|c|c|c|}
\hline $\mathbf{A}$ & $0 \mathrm{~mol} \mathrm{~L}^{-1} \mathrm{NaCl}$ & $0.8 \mathrm{~mol} \mathrm{~L}^{-1} \mathrm{NaCl}$ & $1 \mathrm{~mol} \mathrm{~L}^{-1} \mathrm{NaCl}$ \\
\hline $\begin{array}{r}\text { pYES2 } \\
\text { PYES2::OsLOL5 }\end{array}$ & & x & क \\
\hline B & $30 \mathrm{mmol}^{\mathrm{L}-1} \mathrm{NaHCO}_{3}$ & $32 \mathrm{mmol}^{\mathrm{L}-1} \mathrm{NaHCO}_{3}$ & $40 \mathrm{mmol}^{\mathrm{L}-1} \mathrm{NaHCO}_{3}$ \\
\hline $\begin{array}{r}\text { pYES2 } \\
\text { PYES2::OsLOL5 }\end{array}$ & & & \\
\hline $\mathrm{C}$ & $3 \mathrm{mmol} \mathrm{L}^{-1} \mathrm{H}_{2} \mathrm{O}_{2}$ & $3.2 \mathrm{mmol} \mathrm{L}^{-1} \mathrm{H}_{2} \mathrm{O}_{2}$ & $3.4 \mathrm{mmol} \mathrm{L}^{-1} \mathrm{H}_{2} \mathrm{O}_{2}$ \\
\hline pYES2 & & & 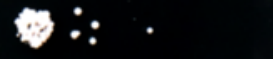 \\
\hline PYES2::OSLOL5 & 89 & & $\because \theta$ \\
\hline
\end{tabular}

Fig. 4 Analysis of the sensitivity of yeast expressing pYES2::OsLOL5 to a $\left(0,0.8\right.$, and $\left.1.0 \mathrm{~mol} \cdot \mathrm{L}^{-1} \mathrm{NaCl}\right) ; \mathbf{b}\left(30,32\right.$, and $\left.40 \mathrm{mmol} \cdot \mathrm{L}^{-1} \mathrm{NaHCO}\right)$; and c $\left(3,3.2\right.$, and $\left.3.4 \mathrm{mmol} \cdot \mathrm{L}^{-1} \mathrm{H}_{2} \mathrm{O}_{2}\right)$. The mean dilution rates of YPD were $10^{0}, 10^{-1}, 10^{-2}, 10^{-3}, 10^{-4}$, and $10^{-5}$
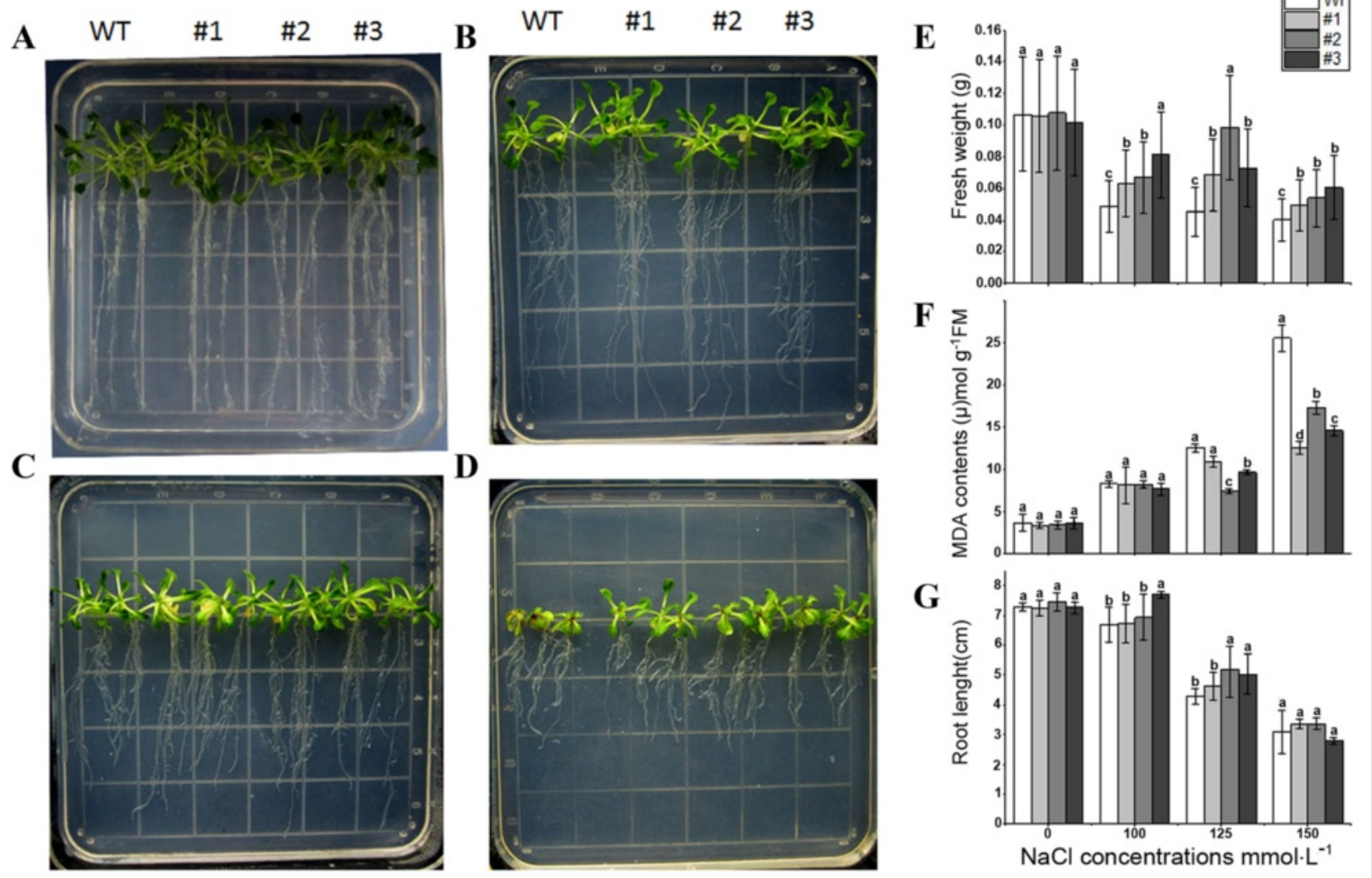

Fig. 5 Analysis of OSLOLS transgenic plants to $\mathrm{NaCl}$ treatment. $\mathbf{a}, \mathbf{b}$, c , and $\mathbf{d}$ show phenotypes of OsLOL 5 transgenic and WT lines subjected to 0 , 100,125 , or $150 \mathrm{mM} \mathrm{NaCl}$ treatment, respectively. $\mathbf{e}, \mathbf{f}$, and $\mathbf{g}$ show fresh weight, endogenous MDA levels, and root length changes in OsLOL5 transgenic and WT lines, respectively 
of INVSc1 yeast containing pYES2 or pYES2-OsLOL5 under the following stresses: $0,0.8$, and $1 \mathrm{~mol} \cdot \mathrm{L}^{-1} \mathrm{NaCl}$; 30, 32, and $40 \mathrm{mmol} \cdot \mathrm{L}^{-1} \mathrm{NaHCO}_{3}$; and 3, 3.2, and $3.4 \mathrm{mmol} \cdot \mathrm{L}^{-1} \mathrm{H}_{2} \mathrm{O}_{2}$ stress. INVSc1 yeast cells containing pYES2 or pYES2-OsLOL5 were cultured in YPD + galactose media plates supplied with different concentrations of $\mathrm{NaCl}, \mathrm{NaHCO}_{3}$, and $\mathrm{H}_{2} \mathrm{O}_{2}$. Growth conditions were observed after $72 \mathrm{~h}$ of incubation at $30{ }^{\circ} \mathrm{C}$ (Fig. 4). As $\mathrm{NaHCO}_{3}$ and $\mathrm{H}_{2} \mathrm{O}_{2}$ concentrations increased, yeast transformed with pYES2-OsLOL5 exhibited better growth conditions than control yeast transformed with pYES2. More clones were clearly present in the pYES2-OsLOL5transformed yeast, particularly in $40 \mathrm{mmol} \cdot \mathrm{L}^{-1} \mathrm{NaHCO}_{3}$ and $3.4 \mathrm{mmol} \cdot \mathrm{L}^{-1} \mathrm{H}_{2} \mathrm{O}_{2}$, than in the control pYES2transformed yeast after dilutions of $10^{-2}$ and $10^{-3}$. However, growth conditions between YES2 and YES2-OsLOL5 were not significantly different under $\mathrm{NaCl}$ treatment. Thus, yeast cells expressing OsLOL5 were more resistant to $\mathrm{NaHCO}_{3}$ and $\mathrm{H}_{2} \mathrm{O}_{2}$ stress.

\section{OsLOL5 overexpression in A. thaliana enhanced SA stress tolerance}

To investigate the biological function of OsLOL5 in plants, we overexpressed OsLOL5 in Arabidopsis under the control of promoter CaMV 35S. PCR screening results showed that the OsLOL5 band was detected in five T1 (\#1-\#5) lines (Additional file 2: Figure S2A), whereas the negative control did not amplify the target gene fragment. These results indicated that the OsLOL5 gene was inserted into the Arabidopsis genome. Furthermore, Northern blot analysis of the T3 transgenic lines derived from the five identified $\mathrm{T} 1$ lines confirmed that OsLOL5 was successfully overexpressed in the Arabidopsis genome (Additional file 2: Figure S2B). Three T3 lines, namely, T3-\#1, -\#2, and -\#3 seedlings, were used for further analysis.

To identify the function of OsLOL5 in stress response, the T3 generation OsLOL5-overexpressing lines were subjected to SA tolerance assay. Under standard culture conditions, no noticeable difference was observed between transgenic lines overexpressing OsLOL5 and nontransformed plants. After $14 \mathrm{~d}$ of $\mathrm{NaCl}$ treatment, both WT and transgenic plants experienced growth retardation in a dose-dependent manner. However, retardation was more apparent in WT plants than in transgenic plants (Fig. 5a, b,c, and d). Moreover, a significant and dramatic difference in fresh weight and root length between the transgenic and WT plants was noted (Fig. 5e, g). Salt stress can cause oxidative damage to cell membranes. MDA content is an indicator of oxidative stress. In the present study, MDA levels in transgenic lines decreased significantly compared with those in WT plants (Fig. 5f).

Similarly, after $14 \mathrm{~d}$ of treatment, $\mathrm{NaHCO}_{3}$ significantly inhibited both transgenic and WT lines (Fig. 6), but the fresh weight of the transgenic lines was significantly higher than that of the WT controls. At high $\mathrm{NaHCO}_{3}$

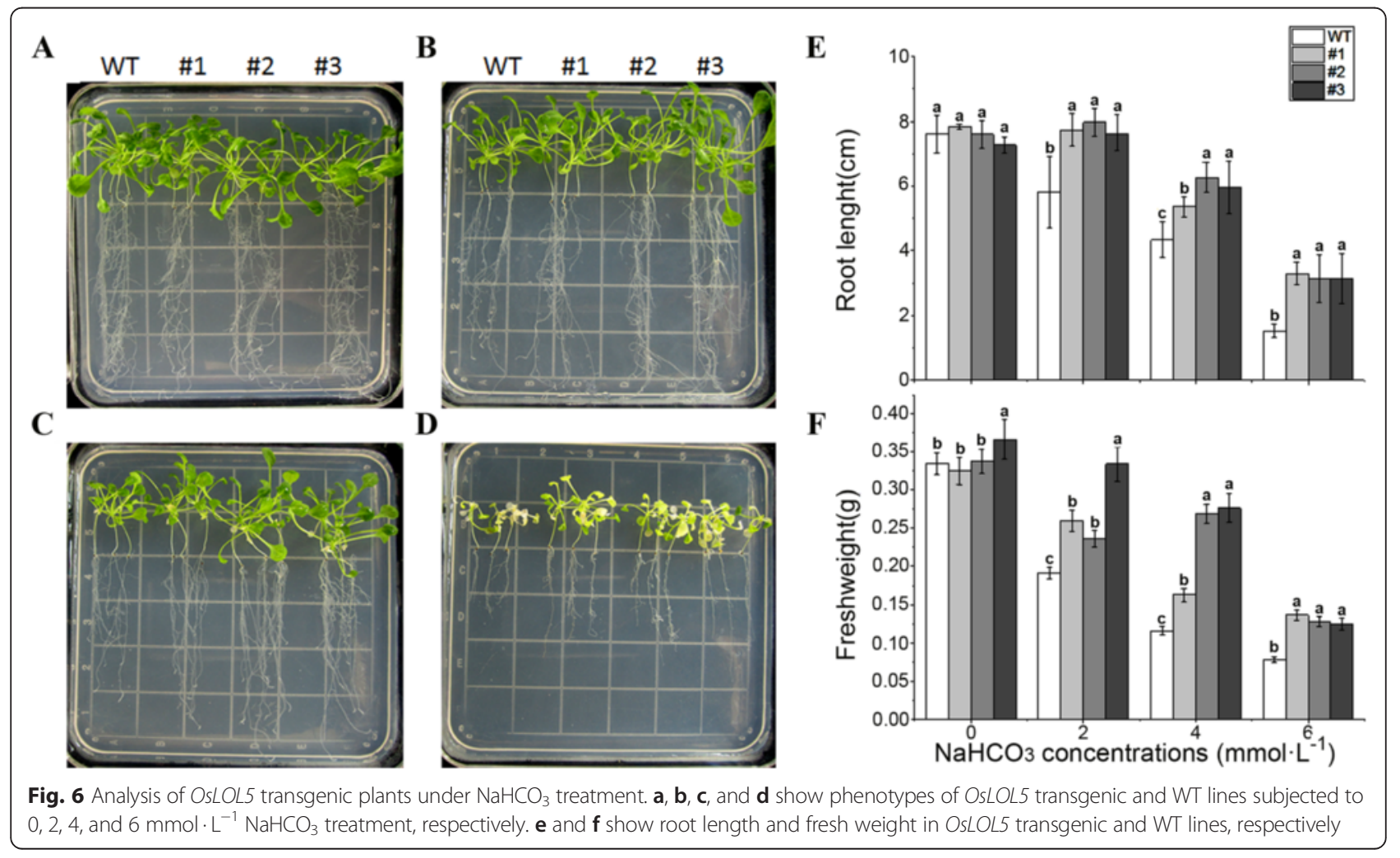


concentrations $\left(4 \mathrm{mmol} \cdot \mathrm{L}^{-1}\right.$ and $\left.6 \mathrm{mmol} \cdot \mathrm{L}^{-1}\right)$, both WT and transgenic plants exhibited chlorosis, but the fresh weight and root length in WT was significantly lower than in OsLOL5 transgenic lines. These results indicated that OSLOL5 played an important role in the stress response, and increased the SA stress tolerance of plants.

\section{OsLOL5 overexpression in rice increased alkaline stress tolerance}

The OsLOL5 gene was introduced in O. sativa L. ssp. cv. "Longjing 11" via Agrobacterium-mediated transformation under the control of promoter CaMV 35S. Six T1 generation (\#1-\#6) OsLOL5 transgenic lines were identified by PCR (Fig. 7b). To detect OsLOL5 expression in transgenic rice lines, Northern blot was performed on young leaves of transgenic and NT rice. OsLOL5 overexpression in different levels was observed in T2 transgenic rice lines \#1, \#2, \#3, and \#5 (Fig. 7c). Responses of transgenic rice lines $(\# 1-\# 3)$ and $\mathrm{NT}$ plants to $\mathrm{NaHCO}_{3}$ stress were determined to further investigate the roles of OsLOL5 in rice. Under standard culture conditions, no noticeable difference between transgenic lines and NT plants was observed. After $21 \mathrm{~d}$ of $\mathrm{NaHCO}_{3}$ treatment, NT plants exhibited growth retardation and chlorosis, whereas OsLOL5 overexpression lines exhibited continuous growth and remained green (Fig. 7a). Moreover, a marked difference in both root length, plant height and fresh weight was observed between transgenic and WT plants (Fig. 7d, e, f). These results further indicated that OsLOL5 played an important role in stress response and increased the $\mathrm{NaHCO}_{3}$ stress tolerance of plants.

\section{Expression of oxidative stress response genes were enhanced in OsLOL5-overexpressing rice}

SA stress can cause oxidative stress, and OsLOL5overexpressing lines show significant alkaline stress tolerance. To verify whether the expression of oxidative stress response genes is also enhanced in these transgenic lines, several oxidative stress response genes (OsAPX2, OsCAT, OsCu/Zn-SOD, and OsRGRC2) were chosen and compared between NT and OsLOL5-overexpressing lines in response to $\mathrm{NaHCO}_{3}$ treatment. Realtime PCR assay indicated that $\mathrm{NaHCO}_{3}$ stress induced
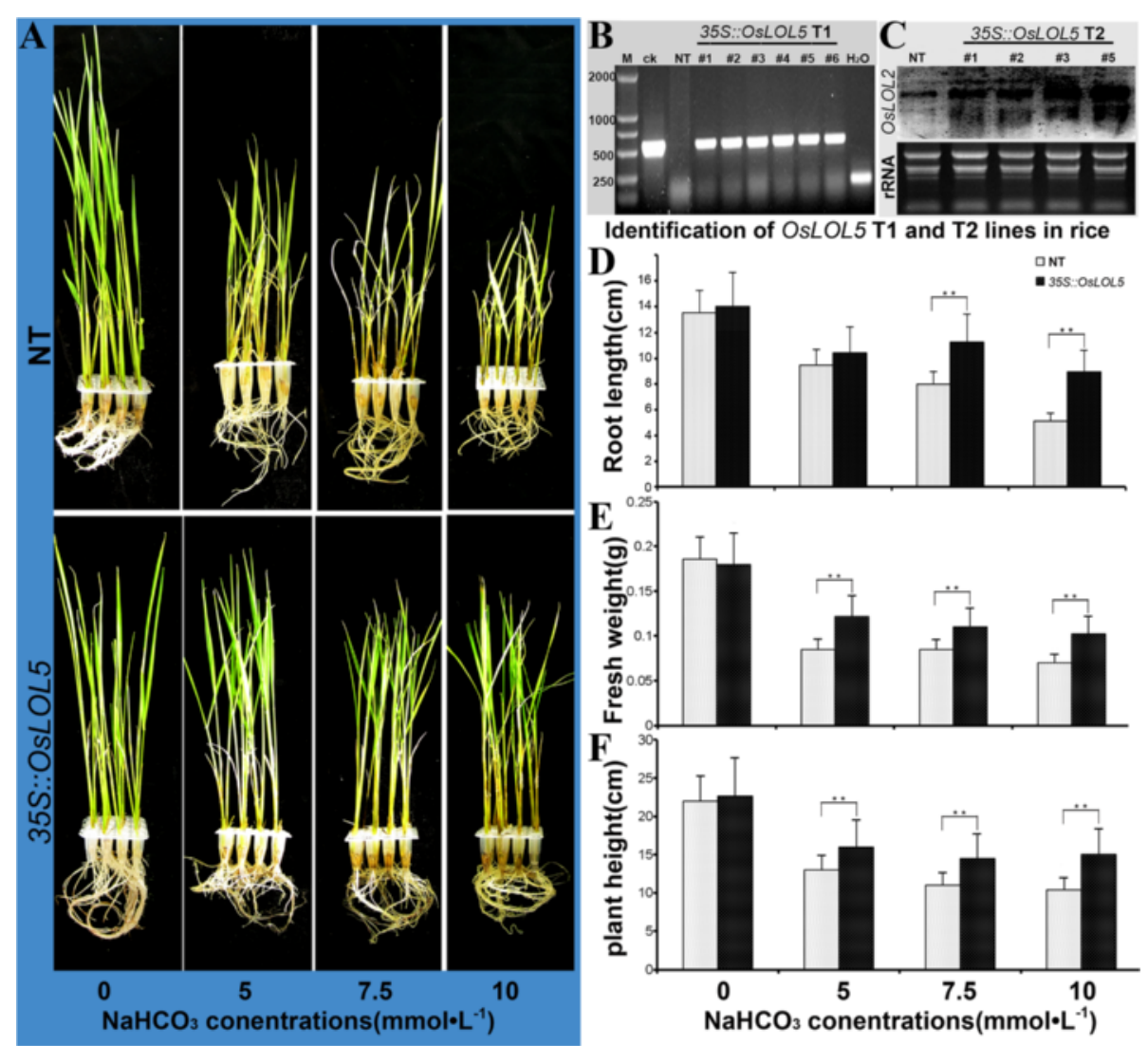

Fig. 7 Analysis of $\mathrm{OSLOLS}$ transgenic rice under $\mathrm{NaHCO}_{3}$ treatment. a shows phenotypes of the OsLOL5 transgenic and NT lines subjected to 0, 5 , 7.5 , or $10 \mathrm{mmol} \cdot \mathrm{L}^{-1} \mathrm{NaHCO}_{3}$ treatment. $\mathbf{b}$ and $\mathbf{c}$ show identification of OsLOL5 T1 and T2 lines in rice. $\mathbf{d}$, e, and $\mathbf{f}$ show root length, fresh weight, and plant height in OsLOL5 transgenic and NT lines. ${ }^{*}$ means significant level $(p<0.01)$ by T-test 
the expression of these genes, and the expression level of oxidative stress response genes in OsLOL5-overexpressing lines was significantly higher than in NT plants (Fig. 8). The expression of $\mathrm{OsCu} / \mathrm{Zn}-\mathrm{SOD}$ genes also were upregulated in the absence of salt stresses. Without $\mathrm{NaHCO}_{3}$ treatment, the expressions of most oxidative stress response genes (OsAPX2, OsCAT, and $\mathrm{OsCu} / \mathrm{Zn}$ $S O D$ ) were still notably higher in the OsLOL5-overexpressing lines than in NT plants. This finding indicated that OsLOL5 overexpression promoted the constitutive expression of oxidative stress response genes. Therefore, higher expression of oxidative stress response genes might also contribute to enhanced stress tolerance of OsLOL5-overexpressing lines.

\section{Discussion}

Plant growth and development may be influenced by biotic and abiotic stress, such as diseases, insects, low temperatures, drought, high salinity, and wounding. Plants have developed many complicated signal transduction and regulatory mechanisms to adapt to environmental changes and to continue to grow and develop under such harsh conditions [24]. ZFP expression can be induced by the cold season, drought, and $\mathrm{H}_{2} \mathrm{O}_{2}$ stress. The OSISAP1ABA gene from Indian rice coding $\mathrm{C} 2 \mathrm{H} 2$ ZFP is expressed under stress conditions, such as high salt, low temperature, and drought; this behavior indicates the relationship between OsISAP1 and abiotic stress [25]. In the present study, the OsLOL5 gene was cloned from rice $\mathrm{cv}$. "Longjing11", which contains two LSD1-like zinc finger domains and shares a high homology with AtLOL2 (Additional file 1: Figure S1). This gene has a typical C-X2-C-X14-C-X2-C structure (Additional file 1: Figure S1). OsLOL2 not only participated in growth development, but was also affected by pathogenic microorganism stress. OsLOL2 overexpression in tobacco enhances resistance to bacterial wilt and $P$. syringae [18]. OsLOL5 gene expression increased in "Longjing11" leaf and Longjing root with SA stress (Fig. 3), thereby indicating that OsLOL5 was a broad spectrumresistant transcription factor. Stress is usually accompanied with high salinity and numerous reactive oxygen species, which can lead to lipid peroxidation of the cell membrane in plants, mutation, DNA strand breaks, and protein
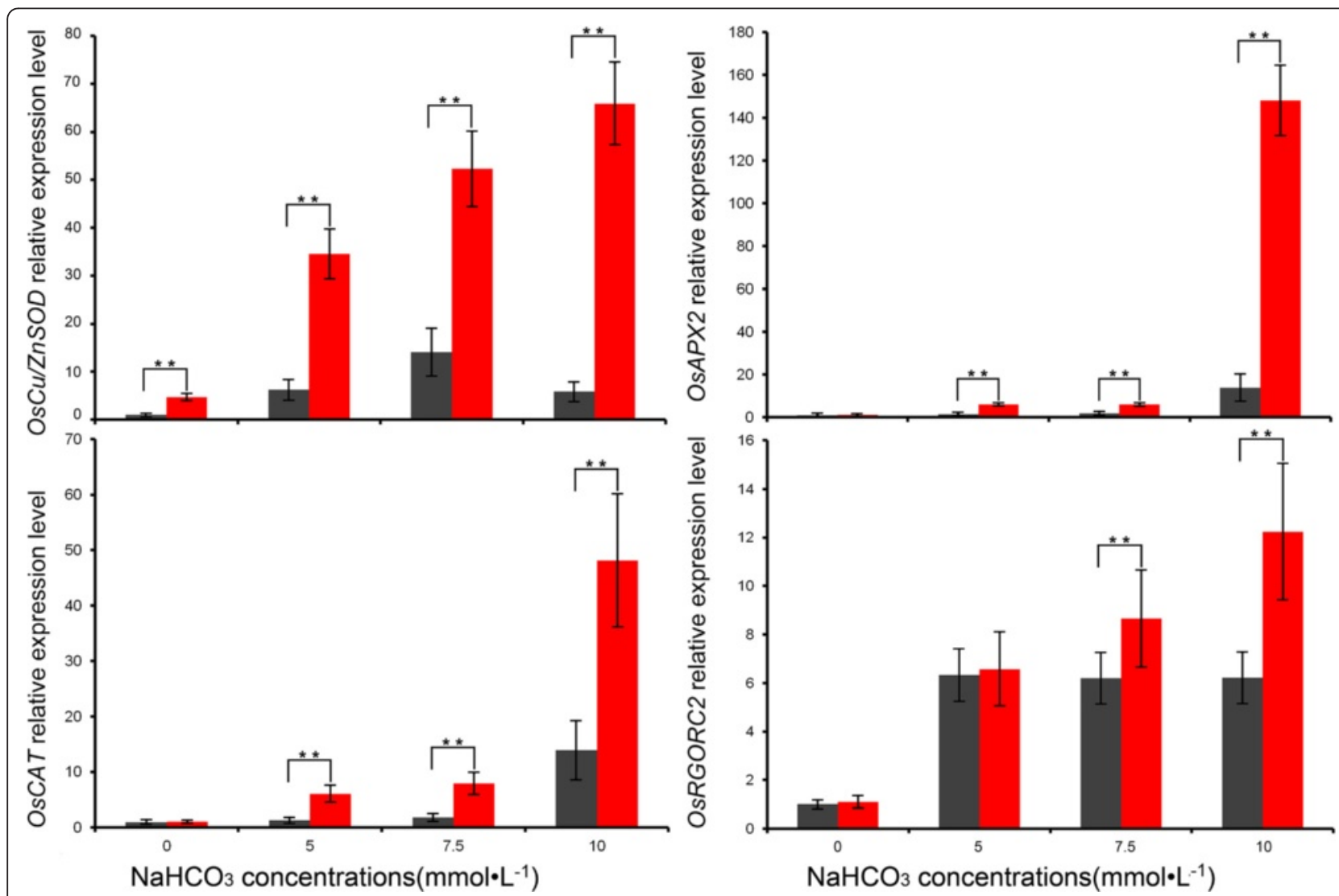

Fig. 8 Expression of stress-related genes in OsLOL5-overexpressing and NT rice. Total RNA was extracted from rice seedlings at the four-leaf stage grown under control and salt treatments. The transcript levels of OsAPX2, OsCAT, OsCu/Zn-SOD, and OsRGRC2 were measured by quantitative realtime PCR under unstressed conditions or $0,5,7.5$, and $10 \mathrm{mmol} \cdot \mathrm{L}^{-1} \mathrm{NaHCO}_{3}$ for $21 \mathrm{~d}$, respectively. Data are written as means and standard errors of three replicates. ${ }^{* *}$ show significant differences at $p<0.01$ (means $\pm \mathrm{SD}, n=6$ ) 
damage. OsLOL5 gene expression increased with $\mathrm{H}_{2} \mathrm{O}_{2}$ stress in rice leaf, which revealed that OsLOL5 may respond to oxidation stress. Future studies may consider predicting which gene can regulate expression to improve tolerance for salinity stress. Experiments confirmed that "Longjing11" OsLOL5 localized and functioned in the nucleus (Fig. 3). Yeast grows quickly, and its experiment cycle is shorter than in plants; when galactosum is induced, it exhibits high expression efficiency [26]. The present study examined the expression of the GAL1 promoter $[27,28]$ to establish the yeast INVScI OsLOL5, and enhanced resistance to SA stress (Fig. 4). The yeast INVScI bacterium grew significantly better than the control strain under $\mathrm{NaCl}$, $\mathrm{NaHCO}_{3}$, and $\mathrm{H}_{2} \mathrm{O}_{2}$ treatments, particularly under $3.2 \mathrm{mM}$ $\mathrm{H}_{2} \mathrm{O}_{2}$ stress. These findings illustrated that OsLOL5 overexpression enhanced yeast resistance for SA stress through active oxygen species.

MPKs can directly modulate ZAT10 gene expression through the phosphorylation of transcription factors [29]. Thirty-four (34) Medicago CCCH Zinc finger genes have been identified in response to PEG-6000, $\mathrm{NaCl}$, and ABA stress conditions [30]. The LSD1-like family is a multi-resistance gene family, although studies have shown that transcription factor OsLOL2 is involved in rice growth and disease resistance [31]. Arabidopsistransferred OsLOL5 strains showed resistance after $14 \mathrm{~d}$ compared with WT grown at 100,125 , and $150 \mathrm{mmol} \cdot \mathrm{L}^{-1}$ $\mathrm{NaCl}$ stress. Under stress treatment, the MDA content of transgenic lines was lower than that of WT. OsLOL5 may be involved in photosynthesis because overexpression strains have high chlorophyll contents. Overexpression of rice also showed resistance to alkaline salts of $\mathrm{NaHCO}_{3}$ (Fig. 8). Overexpression of Longjing11 rice line under $7.5 \mathrm{mmol} \cdot \mathrm{L}^{-1}$ and $10 \mathrm{mmol} \cdot \mathrm{L}^{-1}$ stress resulted in significantly higher $(p<0.01)$ height, fresh weight, and chlorophyll content than Longjing 11. QRT-PCR detection of rice treated with $\mathrm{NaHCO}_{3}$ showed that OsAPX2, OsCAT, $O s C u / Z n-S O D$, and OsRGRC2 genes were transcribed. These genes were induced in both transgenic and NT lines, but the increased rate in transgenic lines was much higher than in NT. The highest expression level was observed in OsAPX2, which was approximately 100-fold of the expression in untreated NT. These results were consistent with results on Arabidopsis AtLSD1 and AtLOL1, which were controlled by negative and positive ROS-mediated signaling pathways, respectively [32]. The present study showed that the OsLOL5 genes involved in the ROS signaling pathways may combine with the model plant Arabidopsis and rice in LDS1-type ZFP by ROS signaling pathways that regulate cell necrosis [12]. We speculated that the OsLOL5 active oxygen scavenging system may have coordinating roles. The present study further revealed that OsLOL5 ZFP could regulate oxidative stress function, but could also provide a basis for salt-resistant rice strains.

\section{Conclusion}

The yeast INVScI bacterium grew significantly better than the control strain under $\mathrm{NaCl}, \mathrm{NaHCO}_{3}$, and $\mathrm{H}_{2} \mathrm{O}_{2}$ treatments. These findings illustrated that OsLOL5 overexpression enhanced yeast resistance for SA stress through active oxygen species. The present study showed that the OsLOL5 genes involved in the ROS signaling pathways may combine with the model plant Arabidopsis and rice in LDS1-type ZFP by ROS signaling pathways that regulate cell necrosis. We speculated that the OsLOL5 active oxygen scavenging system may have coordinating roles. The present study further revealed that OsLOL5 ZFP could regulate oxidative stress function, but could also provide a basis for salt-resistant rice strains.

\section{Additional files}

Additional file 1: Figure S1. Homology alignment of OsLOL5 protein with other LOL proteins from Arabidopsis and Rice. Zf-LSD1:C4-zinc finger domain was marked with *. OsLOL2 (LOC_Os12g41700), OsLOL3 (Q6ASS2), AtLSD1 (At4g20380), OsLOL4 (Q84UR0), OsLSD1 (LOC_Os08g06280), AtLOL1 (At1g32540), OsLOL5 (AJ620677), AtLOL2 (At4g21610). (JPG $2330 \mathrm{~kb}$ )

Additional file 2: Figure S2. PCR analysis of OSLOL5-overexpressing $T 1$ and T3 strains. Northern hybridization of (A) WT: wild-type Arabidopsis thaliana; \#1-\#5: T1 OsLOL5-overexpressing A. thaliana strain; (B) WT: wildtype A. thaliana; \#1-\#3: T3 OsLOL5-overexpressing A. thaliana strain. (JPG $55 \mathrm{~kb}$ )

\section{Abbreviations}

ABA: Abscisic acid; CaMV: Cauliflower mosaic virus; LJ11: LongJing11: MDA: Malondialdehyde; MS: Murashige and Skoog; NT: Non-transgenic rice; SA: Saline-alkaline; WT: Wild type; ZFPs: Zinc finger proteins.

\section{Competing interests}

I confirm that I have read BioMed Central's guidance on competing interests and have included a statement in the manuscript indicating that none of the authors have any competing interests.

\section{Authors' contribution}

QJG and HYM contributed equally to this research. QJG and SKL conceived and designed the experiments. QJG, HYM, ZJW, ZYW and QYB conducted the experiments and analyzed data. ZYW and QYB contributed reagents and materials. QJG, HYM, ZJW, ZYW and SKL wrote the manuscript. All authors have read and approved the final manuscript.

\section{Acknowledgments}

This work was supported by the National High Technology Research and Development Program of China (Grant No. 2013AA102701-7), the Program for Chang jiang Scholars and Innovative Research Team in University (IRT13053) and Scientific Research Foundation for the Returned Overseas Chinese Scholars, Heilongjiang Province (LC2013C10). The funders had no role in the study design, data collection and analysis, decision to publish, and manuscript preparation.

\section{Author details}

${ }^{1}$ Key Laboratory of Saline-alkali Vegetation Ecology Restoration in Oil Field (SAVER), Ministry of Education, Alkali Soil Natural Environmental Science Center (ASNESC), Northeast Forestry University, No.26 Hexing Road, Nangang District, Harbin City, Heilongjiang 150040, China. ${ }^{2}$ Lab of Soybean Molecular Biology and Molecular Breeding, Northeast Institute of Geography and Agroecology, Chinese Academy of Sciences, No.138 Haping Road, Nangang District, Harbin City, Heilongjiang 150081, China. 


\section{Received: 29 September 2015 Accepted: 10 February 2016}

\section{Published online: 27 February 2016}

\section{References}

1. Wang $L$, Pei $Z$, Tian $Y, H e C$. OsLSD1, a rice zinc finger protein, regulates programmed cell death and callus differentiation. Mol Plant Microbe Interact. 2005:18(5):375-84.

2. Kiełbowicz MA. Involvement of plant $\mathrm{C} 2 \mathrm{H} 2$-type zinc finger transcription factors in stress responses. Plant Sci. 2012;185:78-85.

3. Chao YH, Kang JM, Sun Y, Yang QH, Wang PQ, Wu MS, et al. Molecular cloning and characterization of a novel gene encoding zinc finger protein from Medicago sativa L. Mol Biol Rep. 2009;36(8):2315-21.

4. Ham BK, Park JM, Lee SB, Kim MJ, Lee IJ, Kim KJ, et al. Tobacco Tsip1, a DnaJ-type Zn finger protein, is recruited to and potentiates Tsi1-mediated transcriptional activation. Plant Cell. 2006;18(8):2005-20.

5. Li CL, Lv J, Zhao X, Ai XH, Zhu XL, Wang MC, et al. TaCHP: a wheat zinc finger protein gene down-regulated by abscisic acid and salinity stress plays a positive role in stress tolerance. Plant Physiol. 2010;154(1):211-21.

6. Liu QL, Xu KD, Ma N, Zeng L, Zhao L. Isolation and functional characterization of DgZFP: a gene encoding a Cys2/His2-type zinc finger protein in chrysanthemum. Mol Biol Rep. 2010;37(2):1137-42.

7. Milla MAR, Townsend J, Chang F, Cushman JC. The Arabidopsis AtDi19 gene family encodes a novel type of Cys2/His2 zinc-finger protein implicated in ABA-independent dehydration, high-salinity stress and light signaling pathways. Plant Mol Biol. 2006;61(1-2):13-30.

8. Tian ZD, Zhang Y, Liu J, Xie $\mathrm{CH}$. Novel potato $\mathrm{C} 2 \mathrm{H}$ 2-type zinc finger protein gene, StZFP1, which responds to biotic and abiotic stress, plays a role in salt tolerance. Plant Biol (Stuttg). 2010;12(5):689-97.

9. Wang HH, Huang JJ, Bi YR. Nitrate reductase-dependent nitric oxide production is involved in aluminum tolerance in red kidney bean roots. Plant Sci. 2010;179(3):281-8.

10. Keiša A, Kānberga K, Gill U, Kleinhofs A, Rostoks N. Cloning and characterization of barley homologues of the Arabidopsis LSD1 gene: putative regulators of hypersensitive response. Acta Univ Latviensis. 2008; 745:87-101.

11. Liu XM, An J, Han HJ, Kim SH, Lim CO, Yun DJ, et al. ZAT11, a zinc finger transcription factor, is a negative regulator of nickel ion tolerance in Arabidopsis. Plant Cell Rep. 2014;33(12):2015-21.

12. Bai PF, Yang Q, Kang ZS, Guo J. Cloning and Characterization of a Zinc Finger Protein Gene TaLOL2 in Wheat. Acta Botanica Boreali-Occidentalia Sinica. 2012;11:002

13. Islam MS, Hur JH, Wang MH. The influence of abiotic stresses on expression of zinc finger protein gene in rice. Russ J Plant Physiol. 2009:56(5):695-701.

14. Huang MD, Wei FJ, Wu CC, Hsing YI, Huang AH. Analyses of advanced rice anther transcriptomes reveal global tapetum secretory functions and potential proteins for lipid exine formation. Plant Physiol. 2009; 149(2):694-707.

15. Huang J, Yang $X$, Wang MM, Tang HJ, Ding LY, Shen $Y$, et al. A novel rice C2H2-type zinc finger protein lacking DLN-box/EAR-motif plays a role in salt tolerance. Biochim Biophys Acta Gene Struct Expr. 2007;1769(4):220-7.

16. Jain M, Tyagi AK, Khurana JP. Constitutive expression of a meiotic recombination protein gene homolog, OsTOP6A1, from rice confers abiotic stress tolerance in transgenic Arabidopsis plants. Plant Cell Rep. 2008;27(4):767-78

17. Huang J, Wang MM, Jiang $Y$, Bao $Y M$, Huang $X$, Sun $H$, et al. Expression analysis of rice A20/AN1-type zinc finger genes and characterization of ZFP177 that contributes to temperature stress tolerance. Gene. 2008;420(2): 135-44.

18. Bhatti $\mathrm{KH}, \mathrm{Xu} \mathrm{CX}, \mathrm{Wu} \mathrm{JH}, \mathrm{He} \mathrm{CZ}$. Overexpression of rice OsLOL2 gene confers disease resistance in tobacco to Pseudomonas syringae pv. tabaci. Prog Nat Sci. 2008;18(7):807-12.

19. Bhatti HH, Shah A, lqbal M, lqbal T, Jiahe W. Transgenic tobacco with rice zinc-finger gene OsLOL2 exhibits an enhanced resistance against bacterialwilt. Australas Plant Pathol. 2011;40(2):133-40.

20. Alinsug MV, Chen FF, Luo M, Tai R, Jiang L, Wu K. Subcellular localization of class II HDAs in Arabidopsis thaliana: nucleocytoplasmic shuttling of HDA15 is driven by light. PLoS One. 2012;7(2):e30846.

21. Chen S, Songkumarn P, Liu J, Wang GL. A versatile zero background Tvector system for gene cloning and functional genomics. Plant Physiol. 2009;150(3):1111-21.
22. Clough SJ, Bent AF. Floral dip: a simplified method for Agrobacteriummediated transformation of Arabidopsis thaliana. Plant J. 1998;16(6):735-43.

23. Peever $T L$, Higgins VJ. electrolyte leakage, lipoxygenase, and lipid peroxidation induced in tomato leaf tissue by specific and nonspecific elicitors from Cladosporium fulvum. Plant Physiol. 1989;90(3):867-75.

24. Hsieh TH, Li CW, Su RC, Cheng CP, Tsai YC, Chan M. A tomato bZIP transcription factor, SIAREB, is involved in water deficit and salt stress response. Planta. 2010;231(6):1459-73.

25. Mukhopadhyay A, Vij S, Tyagi AK. Overexpression of a zinc-finger protein gene from rice confers tolerance to cold, dehydration, and salt stress in transgenic tobacco. Proc Natl Acad Sci U S A. 2004;101(16):6309-14.

26. Tanaka T, Taniyama C, Arai K, Masai H. ATPase/helicase motif mutants of Escherichia coli PriA protein essential for recombination-dependent DNA replication. Genes Cells. 2003;8(3):251-61.

27. Cunningham KW, Fink GR. Calcineurin inhibits VCX1-dependent $\mathrm{H}+/ \mathrm{Ca} 2+$ exchange and induces Ca2+ ATPases in Saccharomyces cerevisiae. Mol Cell Biol. 1996;16(5):2226-37.

28. Giniger E, Varnum SM, Ptashne M. Specific DNA binding of GAL4, a positive regulatory protein of yeast. Cell. 1985;40(4):767-74.

29. Nguyen XC, Kim SH, Lee K, Kim KE, Liu XM, Han HJ, et al. Identification of a C2H2-type zinc finger transcription factor (ZAT10) from Arabidopsis as a substrate of MAP kinase. Plant Cell Rep. 2012;31(4):737-45.

30. Zhang C, Zhang H, Zhao Y, Jiang H, Zhu S, Cheng B, et al. Genome-wide analysis of the $\mathrm{CCCH}$ zinc finger gene family in Medicago truncatula. Plant Cell Rep. 2013;32(10):1543-55.

31. $\mathrm{Xu} \mathrm{C}, \mathrm{He} \mathrm{C}$. The rice OsLOL2 gene encodes a zinc finger protein involved in rice growth and disease resistance. Mol Genet Genomics. 2007;278(1):8594(10).

32. Epple P, Mack AA, Morris VRF, Dangl JL. Antagonistic control of oxidative stress-induced cell death in Arabidopsis by two related, plant-specific zinc finger proteins. Proc Natl Acad Sci. 2003;100(11):6831-6. 